\title{
A new perspective on the infrared brightness temperature distribution of the deep convective clouds
}

\author{
Rakesh Teja Konduru ${ }^{1, *}$, C M Kishtawal ${ }^{2}$ and Shivani Shah ${ }^{3}$ \\ ${ }^{1}$ Centre for Earth, Atmosphere, and Weather Modification Technologies (CEAWMT), Jawaharlal Nehru \\ Technological University, Hyderabad 500 084, India. \\ ${ }^{2}$ Atmospheric and Oceanic Sciences Group, EPSA, Space Applications Centre, Ahmedabad 380 015, India. \\ ${ }^{3}$ Database 83 Web-based Software Division, Space Applications Centre, Ahmedabad 380 015, India. \\ ${ }^{*}$ Corresponding author.e-mail: rakeshtejak@gmail.com
}

\begin{abstract}
We are proposing a statistical technique to analyze the best fit of the histogram of infrared brightness temperature of convective cloud pixels. For this we have utilized the infrared brightness temperatures (IRTB) of Kalpana-1 (8 km resolution) and globally merged infrared brightness temperatures of Climate Prediction Centre NCEP/NWS (4 km resolution, merged from all the available geostationary satellites GOES-8/10, METEOSAT-7/5 and GMS), for both deep convective and non-deep convective (shallow cloud) cases. It is observed that Johnson SB function is the best continuous distribution function in explaining the histogram of infrared brightness temperatures of the convective clouds. The best fit is confirmed by Kolmogorov-Smirnov statistic. Johnson SB's distribution of histogram of infrared brightness temperatures clearly discriminates the cloud pixels of deep convective and non-deep convective cases. It also captures the asymmetric nature in histogram of infrared brightness temperatures. We also observed that Johnson SB distribution of infrared brightness temperatures for deep convective systems is different in each of the pre-monsoon, monsoon and post-monsoon seasons. And Johnson SB parameters are observed to be best in discriminating the Johnson SB distribution of infrared brightness temperatures of deep convective systems for each season. Due to these properties of Johnson SB function, it can be utilized in the modelling of the histogram of infrared brightness temperature of deep convective and non-deep convective systems. It focuses a new perspective on the infrared brightness temperature that will be helpful in cloud detection, classification and modelling.
\end{abstract}

\section{Introduction}

In tropics, deep convective system is the important driving element of large-scale atmospheric circulation, relocation of energy and moisture, continuance of hydrological cycle, and the overall climate of the earth-atmospheric system. Deep convection is the most effective mechanism for the transport of heat and moisture from the atmospheric boundary layer to the upper troposphere. These deep convective clouds are dominant pinpointing tools of atmospheric features on all times and space scales. The convective clouds can be identified in satellite imagery especially in infrared imagery with their very cold cloud tops and by rapid areal expansion of the anvil region. For the identification of convective clouds in satellite imagery, the prime objective is to extract cloud information

Keywords. Johnson SB continuous function; infrared brightness temperature (IRTB), Kolmogorov-Smirnov statistic. 
('cloud screening') from the digital satellite images (Koslowsky 1997). This task of extraction of cloud information and discriminating it with its background is somewhat cumbersome and there are some techniques that can perform such extraction of cloud features from imageries. Those techniques include threshold technique, histogram technique, pattern recognition technique, multispectral technique, radiative transfer technique, etc (Stanley and Thomas 1995).

This study is focused on the threshold technique and histogram technique to analyze the infrared brightness temperature (IRTB) distribution in the digital images of convective clouds. We tried to explore the type of statistical continuous distribution function that exactly fit the IRTB distribution of different convective systems that developed in premonsoon, monsoon and post-monsoon seasons. It shall give a view of behaviour of IRTB of convective systems in different seasons. This may contribute in the forecasting of convective systems by using IRTB distribution. By observing the brightness distribution of the clouds, it is possible to identify the brighter part in the histogram through threshold technique (Koren and Joseph 2000). With this study, we tried to focus on the classification or screening of IRTB in the digital images of convective clouds, only by using continuous statistical functions. There are some better methods to detect and classify the clouds based on the multispectral characteristics of clouds (Seze and Desbois 1987). The bispectral scheme, using visible and infrared band is a common method (Minnis and Harrison 1984). In this paper, we aimed not to compare the method that we proposed with the historical methods for cloud discrimination or screening. But we tried to convince by introducing a new statistical continuous function to classify the IRTB of convective clouds with improved effectiveness. This will be very much helpful in the modelling of IRTB, that may enhance the forecasting and nowcasting of the deep convective systems. And this may give supplementary information for better understanding of the convective cloud development and its advection only by using infrared brightness temperatures.

\section{Data and methodology}

In order to investigate the IRTB distribution we have considered infrared imageries in the southwest sector $\left(10^{\circ}-20^{\circ} \mathrm{N}\right.$ and $\left.75^{\circ}-85^{\circ} \mathrm{E}\right)$ over India, of the Kalpana-1 data (see figure 1, sample data). Kalpana-1 carried Very High Resolution Radiometer (VHRR) as its payload. The payload VHRR consists of three-channels with water vapour channel
TIR BRIGHTNESS TEMPERATURE $19 M A Y 20091100$ UTC

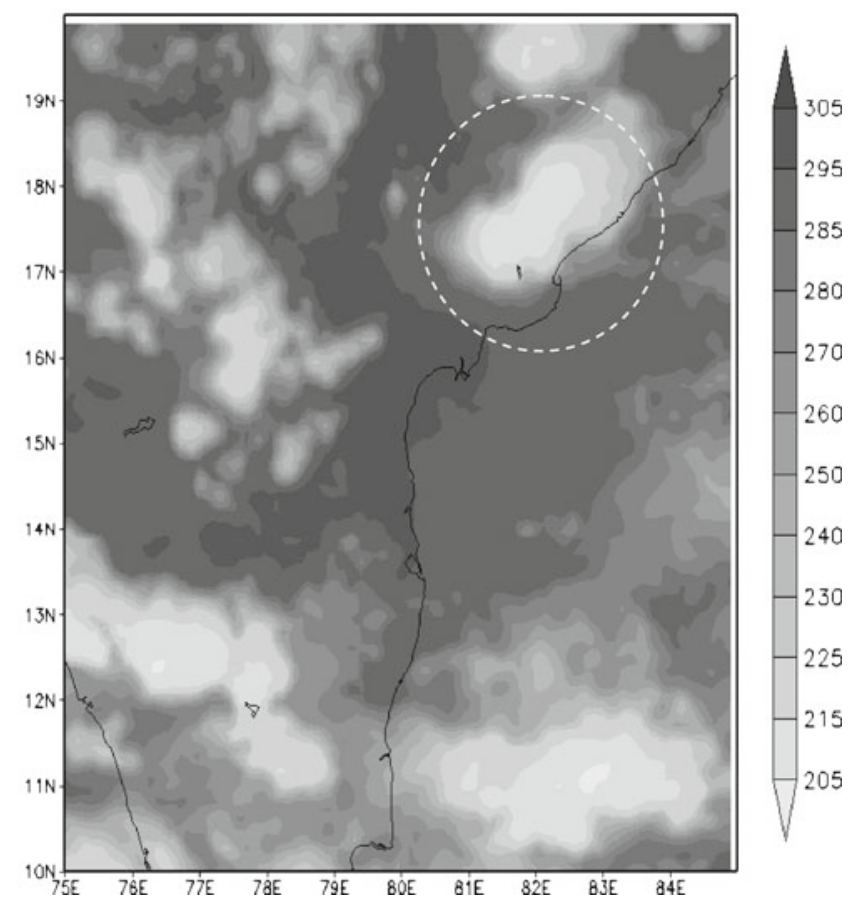

Figure 1. IRTB image of Kalpana-1 for south-east sector $\left(10^{\circ}-20^{\circ} \mathrm{N}\right.$ and $\left.75^{\circ}-85^{\circ} \mathrm{E}\right)$ of India, on 09SEP2012 0430UTC. The deep convective system is shown in the region under the circle.

(WV) 5.7-7.1 $\mu \mathrm{m}$ added to the visible channel (VIS) $0.55-0.75 \mu \mathrm{m}$ and thermal infra-red channel (TIR) 10.5-12.5 $\mu \mathrm{m}$ with a ground resolution of 8,4 and $8 \mathrm{~km}$, respectively. Study region is the south-west sector $\left(10^{\circ} \times 10^{\circ}\right)$ of India (see figure 1$)$. We have taken IRTB data of Kalpana-1 for three different seasons: pre-monsoon (April-May), monsoon (June-September), and post-monsoon (October-November). This data consists of cases for convective systems (see table 1). We have also considered brightness temperature data for clear sky cases. This is to observe how the IRTB distribution can discriminate the convective and clear sky cases. For validation of the work over Kalpana-1 data, we have considered four cases for each of the above-mentioned domain, in which globally-merged IRTB data (4 km resolution) of Climate Prediction Centre NCEP/NWS, merged from all the available geostationary satellites (GOES-8/10, METEOSAT-7/5 and GMS). The availability of data from METEOSAT-7, which is located at $57^{\circ} \mathrm{E}$ at the present time, yields a unique opportunity for tropical coverage. In each convective case, we have extracted infrared brightness temperature pixels of convective systems only (see figure 7 ), of dimension $\left(2^{\circ} \times 2^{\circ}\right)$ (this dimension is to accommodate approximately the whole system). The sample size of each $2^{\circ} \times 2^{\circ}$ region on an average is 2252 . 
Table 1. The number of cases considered for each season and region of development of convective system.

\begin{tabular}{|c|c|c|c|c|}
\hline $\begin{array}{l}\text { Date_time } \\
\text { (UTC) }\end{array}$ & $\begin{array}{l}\text { Sample } \\
\text { size }\end{array}$ & $\begin{array}{c}\text { Region } \\
(\text { degrees })\end{array}$ & $\begin{array}{c}\text { System region } \\
\text { (degrees) }\end{array}$ & $\begin{array}{l}\text { Sample } \\
\text { size }\end{array}$ \\
\hline \multicolumn{5}{|l|}{ Pre-monsoon } \\
\hline 1) 21APR2010_1302 & 17952 & $10 * 10$ & $2 * 2$ & 2224 \\
\hline 2) 22APR2011_0000 &, &, &, & 2288 \\
\hline 3) 24APR2012_1700 &, &, &, & 2210 \\
\hline 4) 01MAY2009_1430 & , & , & , & 2207 \\
\hline 5) 04MAY2010_1630 &, &, &, & 2212 \\
\hline 6) 17MAY2012_1330 & , & , & , & 2232 \\
\hline 7) 20MAY2011_1830 & , & , & , & 2202 \\
\hline 8) 25MAY2011_2011 & , &, &, & 2202 \\
\hline 9) 30MAY2011_1800 & , & , & , & 2206 \\
\hline \multicolumn{5}{|l|}{ Monsoon } \\
\hline 1) 04JUN2010_2100 & 17952 & $10 * 10$ & $2 * 2$ & 2223 \\
\hline 2) 05JUN2010_0000 &, &, &, & 2233 \\
\hline 3) 31AUG2012_0000 &, & , & , & 2280 \\
\hline 4) 26AUG2012_0000 & , &, &, & 2203 \\
\hline 5) 27AUG2012_1230 & , & , & , & 2265 \\
\hline 6) 03SEP2012_0900 &, &, &, & 1928 \\
\hline 7) 06SEP2012_1200 &, &, &, & 2064 \\
\hline 8) 09SEP2012_0030 & , &, &, & 2203 \\
\hline 9) 29AUG2012_0000 & , &, &, & 2278 \\
\hline \multicolumn{5}{|l|}{ Post-monsoon } \\
\hline 1) 23OCT2011_1200 & 17952 & $10 * 10$ & $2 * 2$ & 2275 \\
\hline 2) 28OCT2011_1200 &, &, &, & 2516 \\
\hline 3) 30OCT2011_1200 &, &, &, & 2234 \\
\hline 4) 30OCT2011_0600 & , &, &, & 2258 \\
\hline 5) 30OCT2011_0800 & , & , &, & 2223 \\
\hline 6) 30OCT2011_1000 &, &, &, & 2258 \\
\hline 7) 31OCT2011_1200 &, &, &, & 2274 \\
\hline 8) 25NOV2011_1200 & , & , & , & 2487 \\
\hline 9) 30NOV2011_1200 &, & , &, & 2258 \\
\hline
\end{tabular}

\subsection{Cloud infrared brightness temperature distribution}

In this study, our prime focus is over the thermal infrared channel (TIR 10.5-12.5 $\mu \mathrm{m}$ ). We have considered images with deep convective systems and non-deep convective systems (see figure 2). We applied histogram technique to discriminate the histograms of both the cases. In histogram technique for each convective and non-deep convective case, we identified and clustered the available number of pixels. In case of deep convective system, the distribution is symmetric or asymmetric and skewed towards left in the histogram. The pixels that skewed towards left in the histogram are clustered as one group (left side ellipse in figure 2) and remaining pixels clustered as another group (right side ellipse in figure 2). For non-deep convective system case, the skewness is towards the right and distribution is asymmetric or symmetric (circle represents a cluster, see figure 2). Then by using threshold technique (see table 2 for criteria used for classification (Roca and Ramanathan 1999)), we classified different clusters into deep convective and non-deep convective cloud pixel clusters (Arking 1964; Koffler et al. 1973). Based on these two techniques we initially identified the clusters and then classified them for the entire data sample that we considered in this study. We have directly considered Kalpana-1 IR channel brightness temperature data that contained the mixed pixels of clouds and land/ocean.

We conducted continuous distribution tests based on several continuous distribution functions. All of the distributions were ranked in descending order on the basis of Kolmogorov-Smirnov statistic (Stephens 1986). We observed that Johnson SB function, Gen. Extreme value function and Weibul function in most of the cases occupied the top five positions. Among those three continuous 


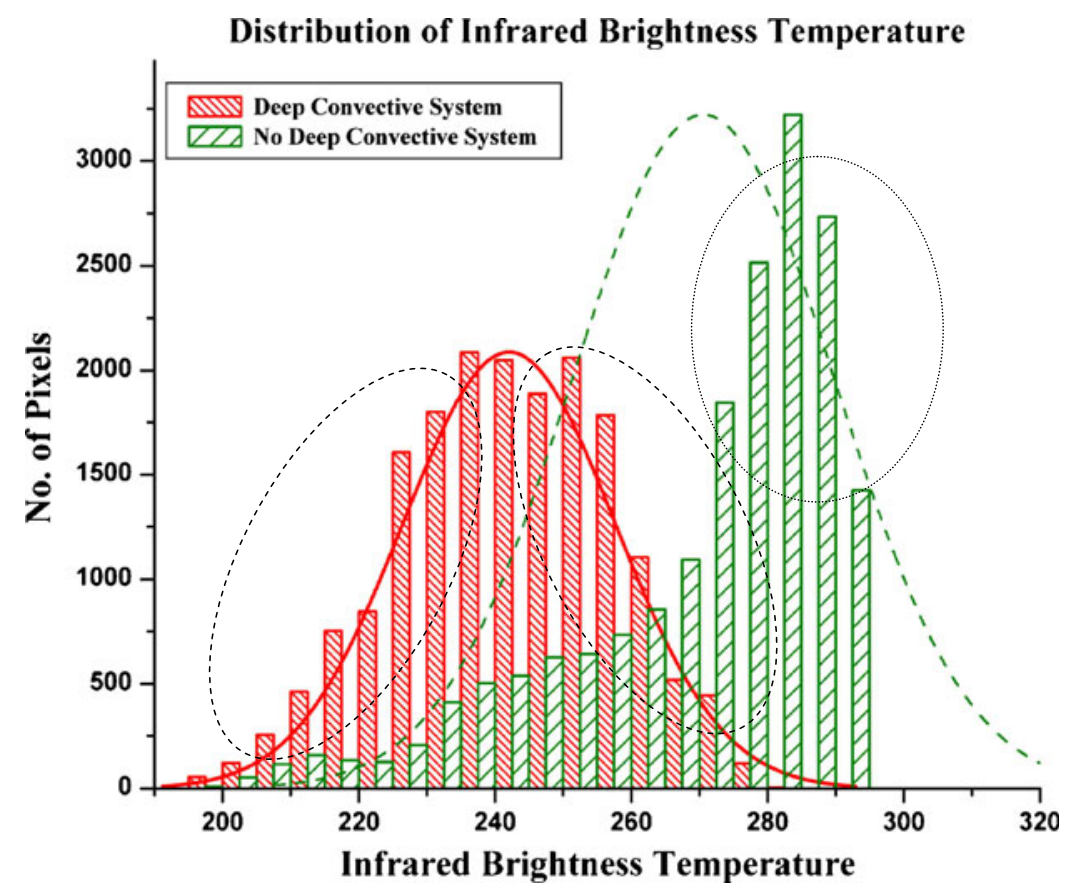

Figure 2. Histogram of infrared brightness temperature in case of deep convective and non-deep convective systems. Here ordinate consists of number of pixels and abscissa consists of infrared brightness temperature. Sample size is 17952 . Here ellipses represents two clusters of pixels in deep convective case and circle represent a cluster of pixels in non-deep convective case.

Table 2. Cloud classification criteria (Roca and Ramanathan 1999).

\begin{tabular}{|c|c|c|c|}
\hline Sl. no. & $\begin{array}{l}\text { IRTB range } \\
\quad\left({ }^{\circ} \mathrm{C}\right)\end{array}$ & $\begin{array}{l}\text { IRTB range } \\
(\mathrm{K})\end{array}$ & Potential cloud types \\
\hline 1 & 0 to 10 & 273 to 283$\}$ & \multirow{2}{*}{$\begin{array}{l}\text { Warm cloud like cumulus } \\
\text { or startus }\end{array}$} \\
\hline 2 & -10 to 0 & 263 to 273$\}$ & \\
\hline 3 & -20 to -10 & 253 to 263 ) & \multirow{3}{*}{ Mixed clouds } \\
\hline 4 & -30 to -20 & 243 to 253 & \\
\hline 5 & -40 to -30 & 233 to 243 & \\
\hline 6 & -50 to -40 & 223 to 233 & \multirow{3}{*}{$\begin{array}{l}\text { Huge mixed clouds like } \\
\text { cumulonimbus (deep } \\
\text { convective clouds) or } \\
\text { cold high clouds }\end{array}$} \\
\hline 7 & -60 to -50 & 213 to 223$\}$ & \\
\hline 8 & $<-60$ & $<223$ & \\
\hline
\end{tabular}

IRTB: Infrared Brightness Temperature.

distributions, Johnson SB function ranked 1 in most of the cases. These details are shown in figure 2 and table 3 . It was observed that Johnson SB continuous distribution function best fits the distribution of the IRTB in both deep convective and non-deep convective cases.

\subsection{Johnson $S B$ distribution function}

As indicated in figure 4, the distribution of IRTB is symmetric in some cases and asymmetric in some other cases. This kind of distribution is shown by Johnson SB function (Johnson et al. 1994). We have tried to construct this kind of distribution by the use of continuous distribution representing statistical function Johnson SB. This continuous distribution fits best the images with pixels of cloud/background.

Johnson SB (Johnson 1949) distribution or, alternately the four parameter lognormal distribution is a probability distribution function for variates constrained by extremes. In some cases, Johnson SB function is related to the normal distribution. Johnson SB distribution is a continuous distribution function defined on bounded range:

$$
\xi \leq x \leq \xi-\lambda
$$

where $\xi$ (continuous location parameter) is the minimum value of $x$ and $\xi-\lambda$ ( $\lambda$ is continuous scale parameter, $>0)$ is the maximum value of $x$ 
Table 3. Goodness-of-fit for distributions of infrared brightness temperature for deep convective system and non-deep convective system cases.

\begin{tabular}{|c|c|c|c|c|c|c|}
\hline \multirow[b]{2}{*}{ Sl. no. } & \multirow[b]{2}{*}{$\begin{array}{l}\text { Continuous } \\
\text { distributions }\end{array}$} & \multicolumn{2}{|c|}{ Non-deep convective system case } & \multirow[b]{2}{*}{$\begin{array}{l}\text { Continuous } \\
\text { distributions }\end{array}$} & \multicolumn{2}{|c|}{ Deep convective system case } \\
\hline & & $\begin{array}{c}\text { Kolmogorov-Smirnov } \\
\text { statistic }\end{array}$ & Rank & & $\begin{array}{c}\text { Kolmogorov-Smirnov } \\
\text { statistic }\end{array}$ & Rank \\
\hline 1 & Johnson SB & 0.081 & 1 & Johnson SB & 0.063 & 1 \\
\hline 2 & Gen. Pareto & 0.083 & 2 & Kumaraswamy & 0.141 & 2 \\
\hline 3 & Fatigue life $(3 \mathrm{P})$ & 0.093 & 3 & Beta & 0.142 & 3 \\
\hline 4 & Log-logistic (3P) & 0.094 & 4 & Gen. extreme value & 0.159 & 4 \\
\hline 5 & Gen. extreme value & 0.096 & 5 & Gen. Pareto & 0.174 & 5 \\
\hline 6 & Frechet & 0.098 & 6 & Weibull (3P) & 0.195 & 6 \\
\hline 7 & Uniform & 0.104 & 7 & Gumbel Min & 0.196 & 7 \\
\hline 8 & Error & 0.104 & 8 & Burr & 0.205 & 8 \\
\hline 9 & Gumbel max & 0.105 & 9 & Log-Pearson3 & 0.207 & 9 \\
\hline 10 & Burr & 0.106 & 10 & Weibull & 0.221 & 10 \\
\hline
\end{tabular}

and the distribution can be symmetric or asymmetric. Probability distribution function of Johnson $\mathrm{SB}$ is defined over bounded range as:

$$
f(x)=\frac{\delta}{\lambda \sqrt{2 \pi} z(1-z)} e^{\left(-\frac{1}{2}\left(\gamma+\delta \ln \left(\frac{z}{1-z}\right)\right)^{z}\right)}
$$

where

$$
z=\frac{x-\xi}{\lambda}
$$

when minimum and maximum values are known a priori, maximum likelihood estimates for the gamma $(\gamma)$ and delta $(\delta, \delta>0)$, which are continuous shape parameters, are

$$
\gamma=\frac{\bar{f}}{s_{f}} \quad \text { and } \quad \delta=-\frac{1}{s_{f}}
$$

where

$$
f=\ln \left(\frac{y}{1-y}\right)
$$

and $\bar{f}$ is the sample mean and

$$
s_{f}=\sqrt{\frac{1}{N} \sum_{i-1}^{N}\left(f_{i}-\bar{f}\right)^{2}} .
$$

When the extremes are unknown a priori, the estimation process becomes more difficult, particularly when all four parameters are to be estimated. Johnson SB function is bounded on both the sides, with exact and apt selection of its parameters, the distribution shape may vary. The location and shape of the hump depends upon the relation between the shape parameters.

Johnson SB distribution has found application in a variety of fields including ambient air pollution (Mage 1980), rainfall distribution (Kotteguda 1987) and forestry (Zhang et al. 2003). But in the context of use of Johnson SB distribution for clouds is not done yet. There are some works where Beta distribution is used in the study of clouds distribution (Falls 1974; Henderson-Sellers 1978). The motive behind the selection of Johnson SB function is to study the distribution of IRTB of clouds and its flexibility to fit both symmetric as well as asymmetric kind of distributions (Johnson and Kitchen 1971). The goodness-of-fit is confirmed by Kolmogorov-Smirnov statistic (see table 3 ). It shows that considered function is the best among all the continuous functions to study the distribution of IRTB of clouds.

For the domains we considered, we tried to utilize the mentioned continuous distribution function in fitting the IRTBs over the domain. Along with the Johnson SB function we have tried to use the goodness of fit of the nine more continuous distributions. The important point in using 10 continuous distributions is to show the best performance of the Johnson SB function against the remaining functions. We have chosen KolmogorovSmirnov test to know the goodness-of-fit of the different distributions. We applied Johnson SB function for more than 150 samples of Kalpana-1 IRTB data over different domains of different areas and observed the distribution of the IRTB. In order to know its applicability in higher resolution of data, since Kalpana-1 infrared channel has a resolution of $8 \mathrm{~km}$ only, we utilized globally-merged IRTB data (4 km resolution) of Climate Prediction Centre NCEP/NWS.

\subsection{Goodness-of-fit tests}

In order to investigate the best fit of the statistical continuous functions, viz., Johnson SB continuous function, we used Kolmogorov-Smirnov test and Shapiro-Wilks test. Kolmogorov-Smirnov test is mainly used for continuous functions. From the 


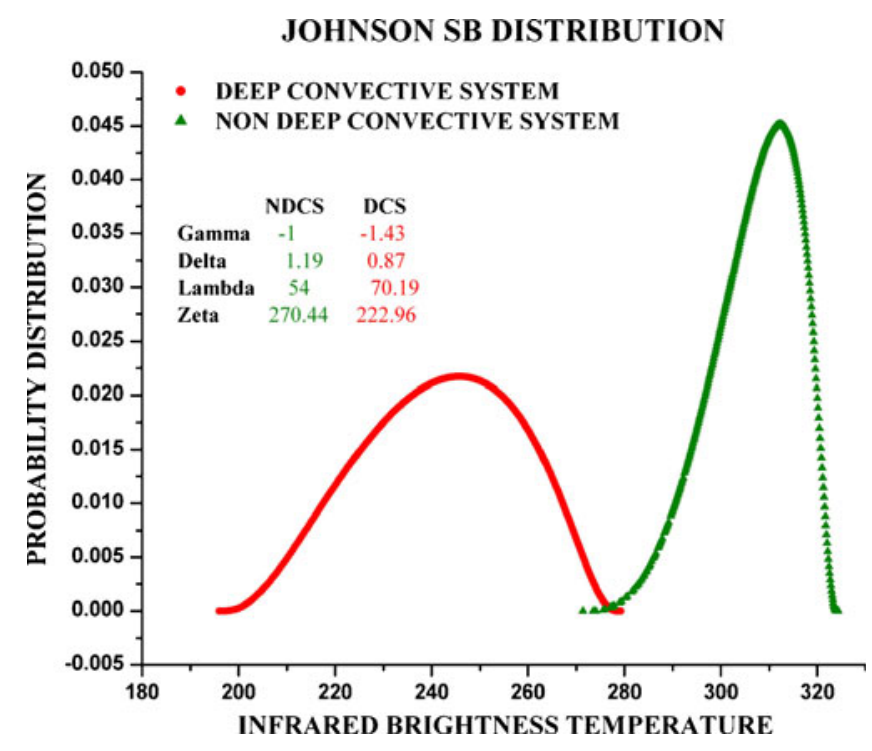

sample of IRTBs, the cumulative distribution $\operatorname{Sn}(x)$ is determined. The cumulative distribution $F(x)$ of the assumed population is determined. The maximum difference between these two distributions:

$$
D=\left|F-S_{n}\right|
$$

It provides the test statistic $D$ and this is compared with the value $D$. If $D>D \alpha$, the null hypothesis that the sample came from the assumed population is rejected. And if the probability value

Figure 3. Johnson SB distributions for infrared brightness temperatures of deep convective system (DCS) and nondeep convective system (NDCS). In this plot, each case possesses sample size of 17952 . In this deep convective case is of 03SEP2012 1200UTC and non-deep convective case is of 02APR2009 0600UTC.

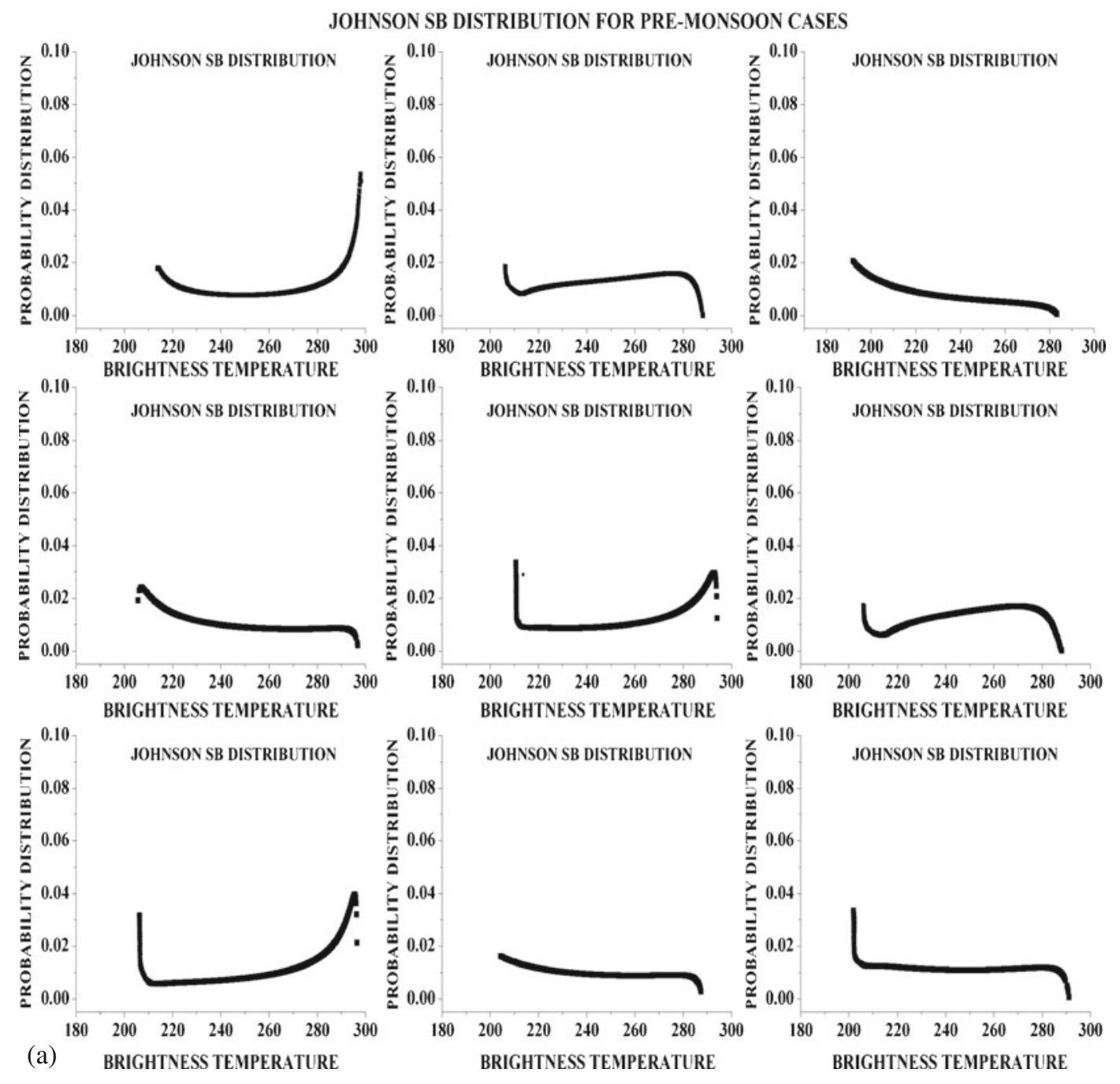

Figure 4. It shows Johnson SB distributions of infrared brightness temperatures of deep convective systems in three different seasons: (a) Pre-monsoon season, (b) monsoon season, and (c) post-monsoon season. Information about sample size and dates are shown in table 1. 
is less than the statistic then the data is not significantly drawn from the normally distributed IRTBs. The Shapiro-Wilks test is the ratio of the best estimator of the variance to the squares estimated of the variance (Shapiro and Wilk 1965). The $W$ statistic is given as:

$$
W=\frac{\left(\sum a_{i} x(i)\right)^{z}}{\sum\left(x_{(i)}-\bar{x}\right)^{z}}
$$

where ' $a$ ' is a vector expected values of standard normal order statistic, and ' $x$ ' is a random sample of IRTBs.

The Shapiro-Wilks test is not reliable for sample size $>5000$. If the probability value is less than the $W$ statistic, then the data is not significantly drawn from the normally distributed IRTB. We used Kolmogorov-Smirnov test for region of $10^{\circ} \times$ $10^{\circ}$ in which sample size is more than 5000. And for $2^{\circ} \times 2^{\circ}$ region we used both KolmogorovSmirnov test and Shapiro-Wilks test. The statistic information of goodness-of-fit test is shown in table 1.

\section{Results and discussions}

We tested our data samples of IRTB over the $10^{\circ} \times 10^{\circ}$ region with the Johnson SB function and also with nine other continuous distribution functions. By using Kolmogorov-Smirnov test, we calculated the statistic of each distribution (see table 3). Based on the statistics (Kanji 2006), it is observed that Johnson SB ranked as 1 (in most of the goodness-of-fit tests). That resembles, Johnson SB fits best the IRTBs (Kalpana-1) of deep convective of cloud (see figure 3 ). The second best continuous distribution function that fits the IRTB data is the Gen. Extreme Value (Gen. EV) function.

JOHNSON SB DISTRIBUTION FOR MONSOON CASES
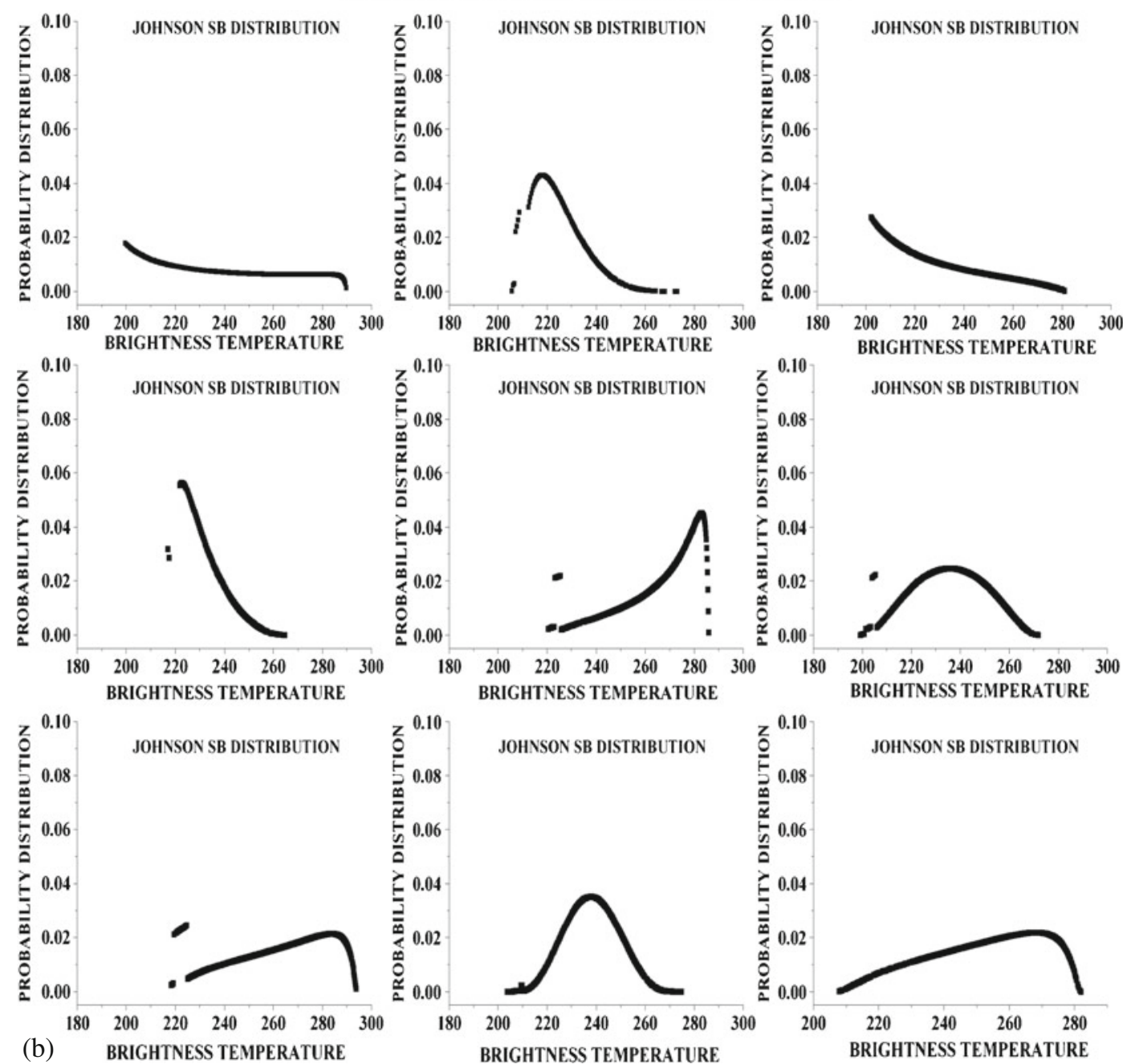

Figure 4. (Continued) 


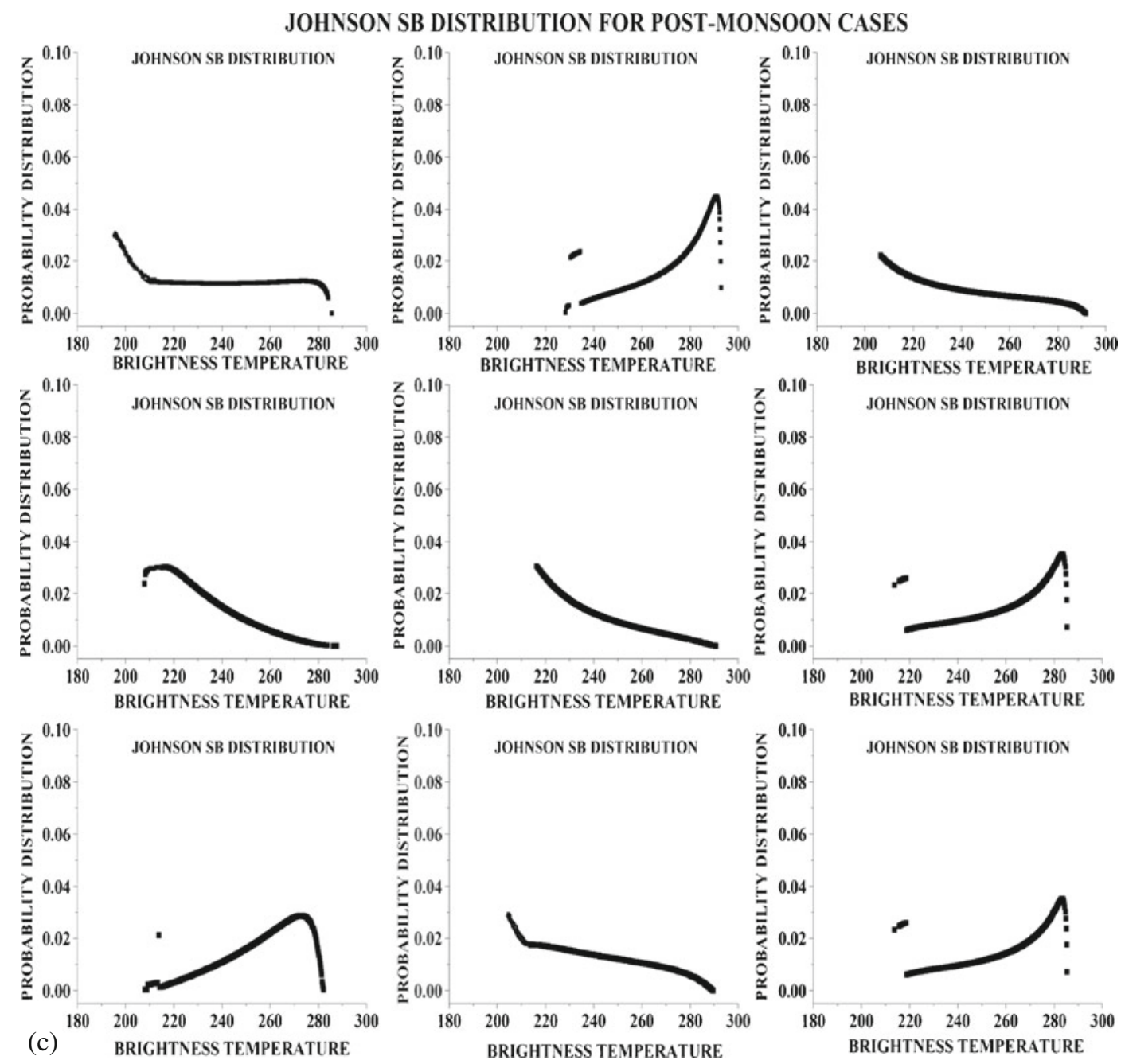

Figure 4. (Continued)

Similarly, in case of non-deep convective system, the Johnson SB distribution of IRTB (Kalpana-1) over the domain (see figure 3 ) is best, and it is confirmed based on the goodness-of-fit of KolmogorovSmirnov statistics (table 3). These results exemplified that the IRTBs of convective cloud can be best fitted by the Johnson SB function. These results are new perspective in the distribution of IRTBs of convective clouds.

Based on the data samples mentioned in table 1, we considered the deep convective system cases in each sample based on the histogram technique and threshold technique that is mentioned in section 2.1 for three seasons, viz., pre-monsoon, monsoon, and post-monsoon. For deep convective case of each sample (see figure 7), we observed the IRTB distribution based on the Johnson SB function. It is observed that Johnson SB distribution of IRTBs of convective systems is different in each season (see figure 4). This difference in the Johnson SB distribution of IRTBs of convective systems shows that the behaviour of IRTBs in convective systems is unique in each season. This kind of uniqueness is also observed in the continuous shape parameters $(\gamma, \delta)$, continuous scale parameter $(\lambda)$, and continuous location parameter $(\xi)$. Among these parameters, continuous shape parameters play very significant role in shaping the Johnson SB distribution of IRTBs (see figure 5). In pre-monsoon season, gamma $(\gamma)$ and delta $(\delta)$ variations are more as compared to the monsoon and post-monsoon seasons. Gamma $(\gamma)$ and delta $(\delta)$ showed more or less similar variations in monsoon and post-monsoon seasons. From this it is clear that continuous shape parameters of Johnson SB function can be effectively used in discriminating the Johnson SB distribution of IRTBs of convective systems in pre-monsoon with monsoon and post-monsoon. The discrimination of convective systems of monsoon and post-monsoon is difficult only by using continuous shape parameters. The lambda $(\lambda)$ variations is observed more in post-monsoon season. Lambda $(\lambda)$ showed not much variations in the monsoon and significant 
GAMMA VARIATION

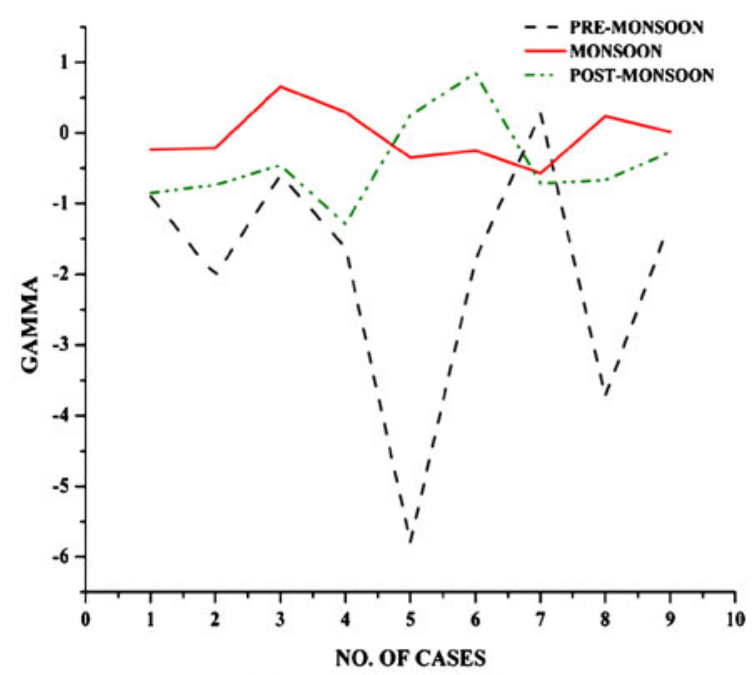

(a) Gamma variation.

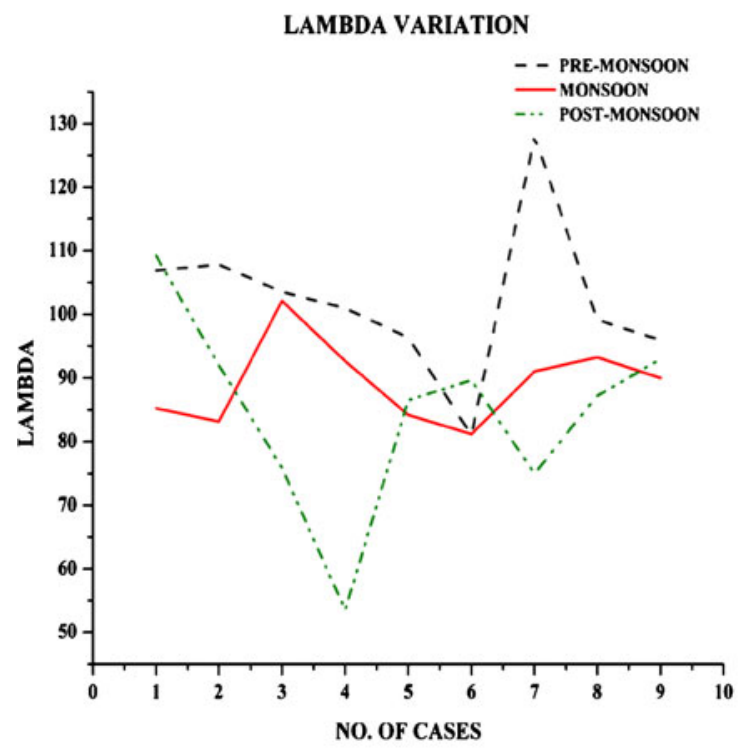

(c) Lambda variation.
DELTA VARIATION

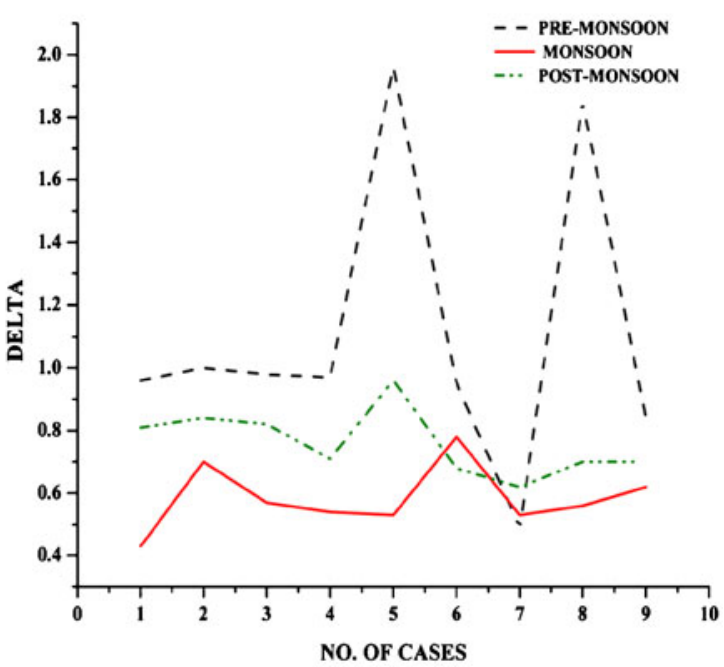

(b) Delta variation.

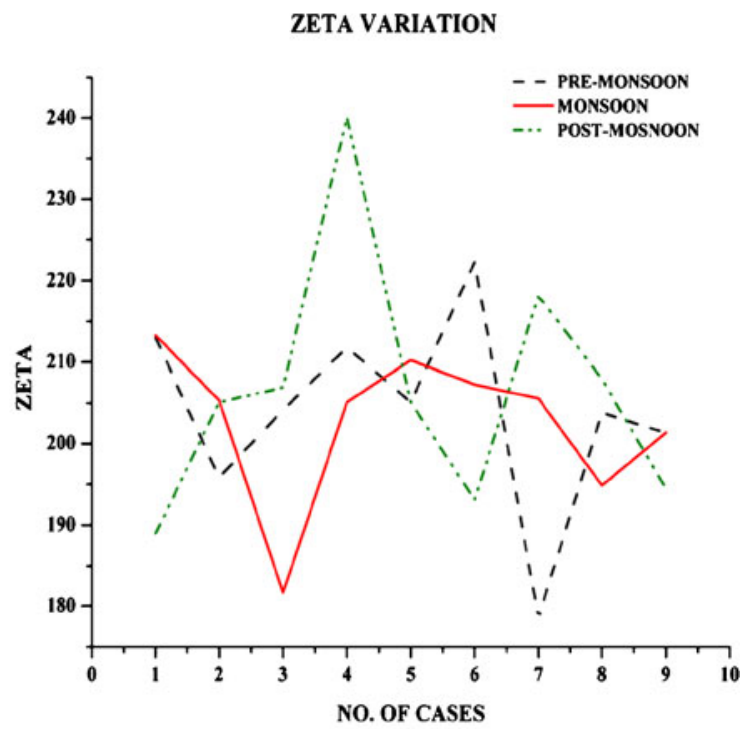

(d) Zeta variation.

Figure 5. It shows variations in the Johnson SB parameters obtained from the distribution of infrared brightness temperatures of deep convective systems in the pre-monsoon, monsoon, and post monsoon seasons. Where gamma $(\gamma)$ and delta $(\delta)$ are the continuous shape parameters; lambda $(\lambda)$ is continuous scale parameter; and zeta $(\xi)$ is continuous location parameter. In each season, eight different deep convective system cases were considered.

variations in pre-monsoon season. Thus lambda $(\lambda)$ can be effectively used in discriminating the Johnson SB distribution of IRTBs of convective systems post-monsoon with monsoon and premonsoon. By using lambda we can discriminate, to some extent, the Johnson SB distribution of IRTBs of convective systems in monsoon with other seasons. The zeta $(\xi)$ showed more variations in postmonsoon season and more or less variations in the monsoon and pre-monsoon seasons. So by using zeta $(\xi)$, the Johnson SB distribution of IRTBs of convective systems of post-monsoon season can be effectively discriminated from convective systems of other seasons. From these results, based on one parameter or combinations of parameters of the Johnson SB function it is observed that the convective systems developed in pre-monsoon, monsoon, and post-monsoon seasons can be discriminated to a large extent from convective systems of each of the seasons. However, to a large extent, Johnson $\mathrm{SB}$ parameters are effective in the distribution of IRTBs of convective systems in each mentioned season.

Johnson SB function also distributes the IRTBs for non-deep convective system cases as well (see figure 3 ). Similar kind of variations in Johnson 


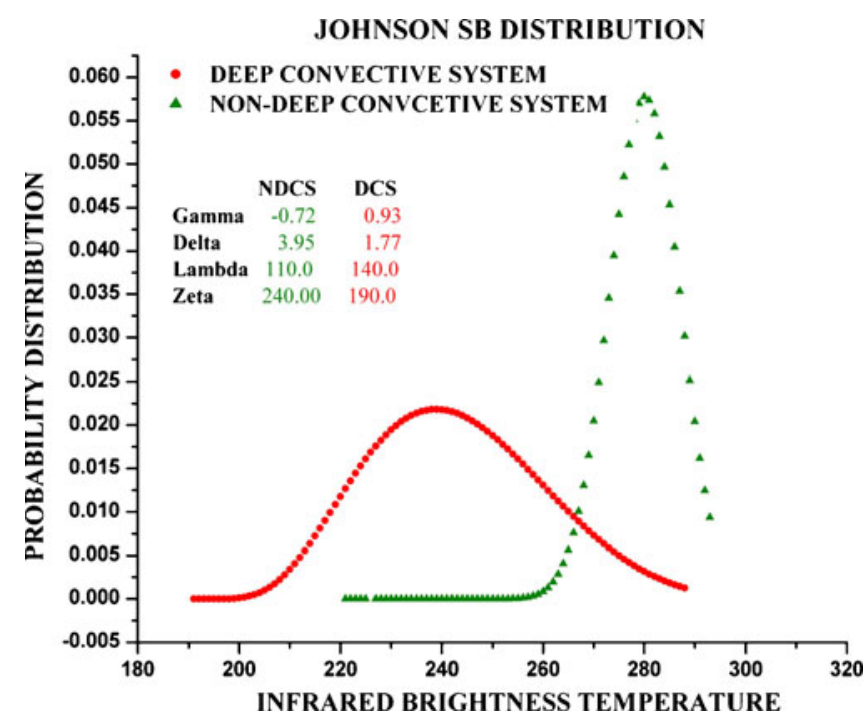

Figure 6. Johnson SB distributions of globally merged infrared brightness temperature of NCEP/NWS for deep convective system (DCS) and non-deep convective system (NDCS). Deep convective system case is of 03SEP2012 1200UTC and non-deep convective system case is of 02SEP2012 00UTC. The sample size of DCS is 78399 and NDCS is 84816.

SB distribution is also observed in the case of globally-merged IRTB data (4 km resolution) of Climate Prediction Centre NCEP/NWS over $10^{\circ} \times$ $10^{\circ}$ region (as considered). For $4 \mathrm{~km}$ resolution data of NCEP/NWS, the Johnson SB function clearly discriminates the histograms of the IRTB of deep convective system and non-deep convective system (see figure 6). This result of applicability of Johnson SB continuous function on globallymerged IRTB data of Climate Prediction Centre NCEP/NWS shows that, Johnson SB function is flexible to distribute IRTBs data of Kalpana-1, GOES-8/10, and METEOSAT-7/5 and GMS satellites as well. This study may be extended for other satellites' IRTBs data to confirm the best fit of Johnson SB continuous function. The raw images of Kalpana-1 IRTB over the domain (that includes convective cases) are shown in figure 7 . We observed that Johnson SB functions distribution is applicable for domains with size of $2^{\circ} \times 2^{\circ}$ region and $10^{\circ} \times 10^{\circ}$ region. These results imply that Johnson SB statistical distribution function is best in distributing IRTB. We also observed that Johnson SB function clearly discriminates the deep convective and non-deep convective system cases very clearly. This result is applicable in forecasting the development of deep convective system by using the Johnson SB parameters. These results encouraged us to think about the applicability of Johnson SB continuous function in modelling the histogram of IRTBs. The IRTBs distribution can be modelled using Johnson SB function and its parameters, and to give it as an input to model, viz., WRF may enhance the forecast probability of the deep convective systems. We may also think about to replace the currently in usage continuous functions like Weibul/Beta/Gamma with Johnson SB function, to study the distribution of IRTBs. This may improve the applicability of IRTBs to model the deep convective systems with improved predictive skills. In simulating IRTBs of clouds of the deep convective systems, the use of Johnson SB distribution may be very much helpful in enhancing the accuracy of simulation of deep convective systems (such simulating model like radiative transfer model, etc). These results reflect the broad scope for the applicability of Johnson SB distribution of IRTBs of convective cloud. But still it requires a better understanding for the type of overlapping between the background and convective clouds IRTB based on the Johnson SB distribution.

\section{Conclusions}

It is evident from the above discussion that Johnson SB continuous distribution is the best to fit the histogram of the IRTB data of both Kalpana-1 and globally merged data of NWAS/ NCEP in both deep convective and non-deep convective cases. And it is evident that it is applicable for a domain of $10^{\circ} \times 10^{\circ}$ region and for $2^{\circ} \times 2^{\circ}$ region as well. The second best fit is by the Gen. Extreme value function. But there is some ambiguity in the Johnson SB function's distribution of IRTB for deep convective and non-deep convective system case (due to type of tail in distribution). We explored that Johnson SB distribution of IRTBs of convective systems is different in each season (pre-monsoon, monsoon, and post-monsoon). The Johnson SB parameters, viz., continuous shape parameters $(\gamma, \delta)$, continuous scale parameter $(\lambda)$, and continuous location parameter $(\xi)$ generated from the Johnson SB distribution were very effective in the distribution of IRTBs of convective systems in each season, viz., pre-monsoon, monsoon, and post-monsoon. The continuous shape parameters of Johnson SB function can be effectively used in discriminating the Johnson SB distribution of IRTBs of convective systems in pre-monsoon with convective systems of other seasons, and not that much effective in case of post-monsoon and monsoon. But to a large extent, lambda and zeta discriminated the distribution of IRTBs of convective systems in post-monsoon with other seasons. From these results, based on one parameter or combinations of parameters of the Johnson SB function, it is observed that the convective systems developed in pre-monsoon, monsoon, and post-monsoon seasons can be discriminated to a large extent 
TIR BRIGHTNESS TEMPERATURE 03SEP2012 1200 UTC

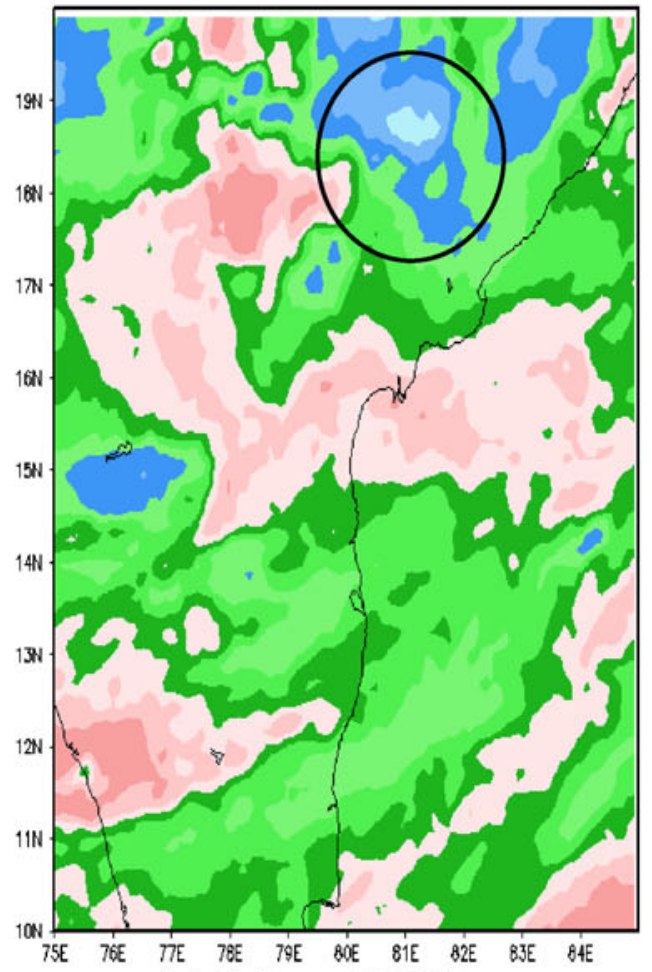

(a) Kalpana-1 IRTB

TIR BRIGHTNESS TEMPERATURE 01SEP2012 0000 UTC

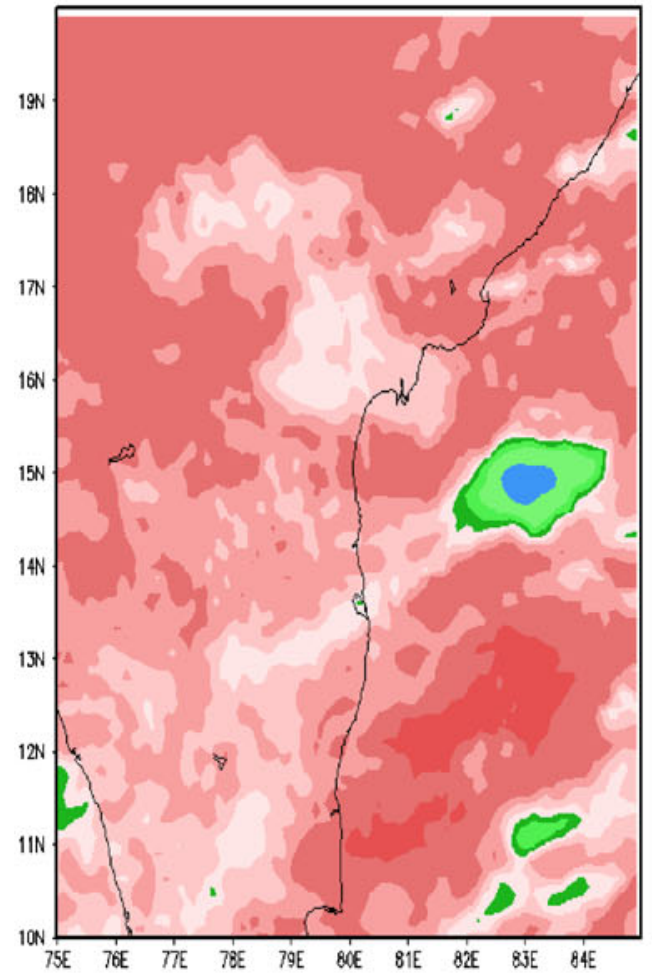

(c) Kalpana-1 IRTB

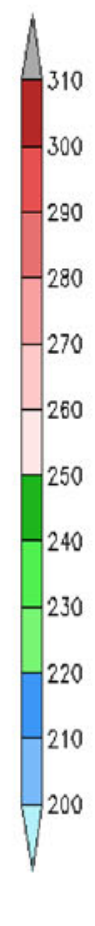

$-280$

$-270$

$-260$

$-250$

$-240$

$-230$

$-220$

$-200$
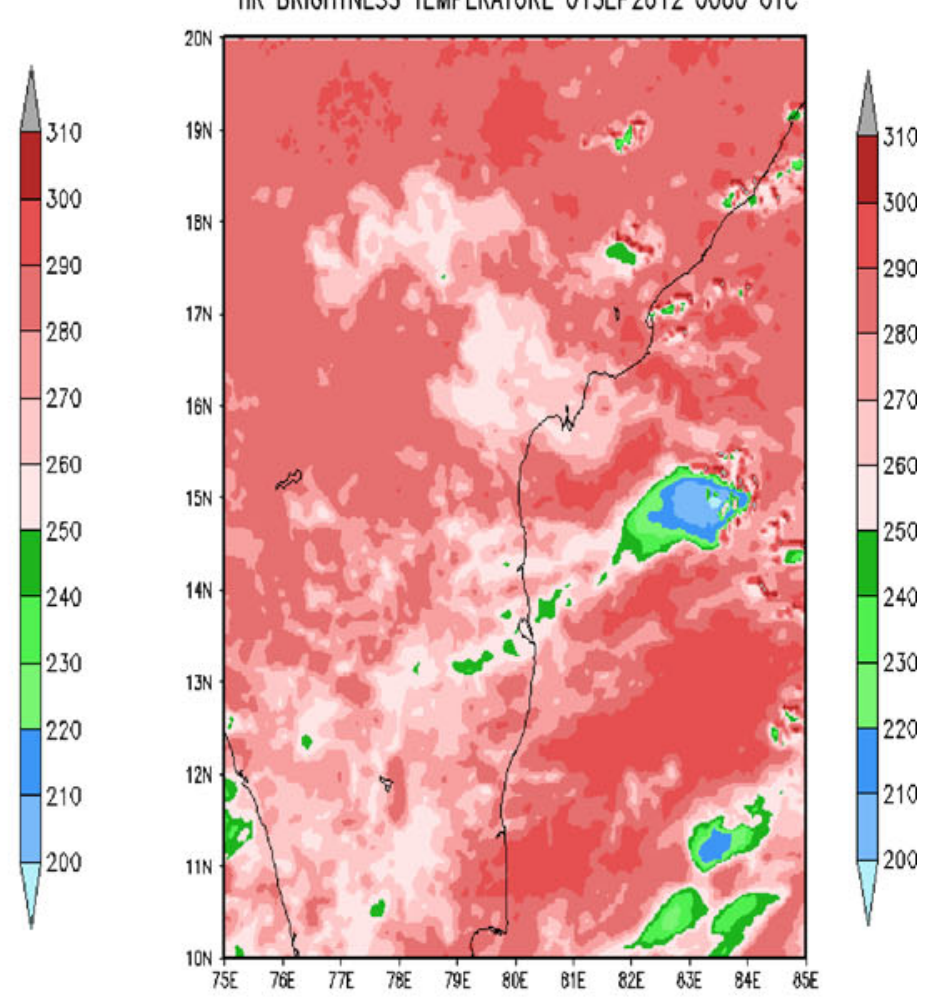

(d) Globally merged IRTB

TIR BRIGHTNESS TEMPERATURE O3SEP2012 1200 UTC

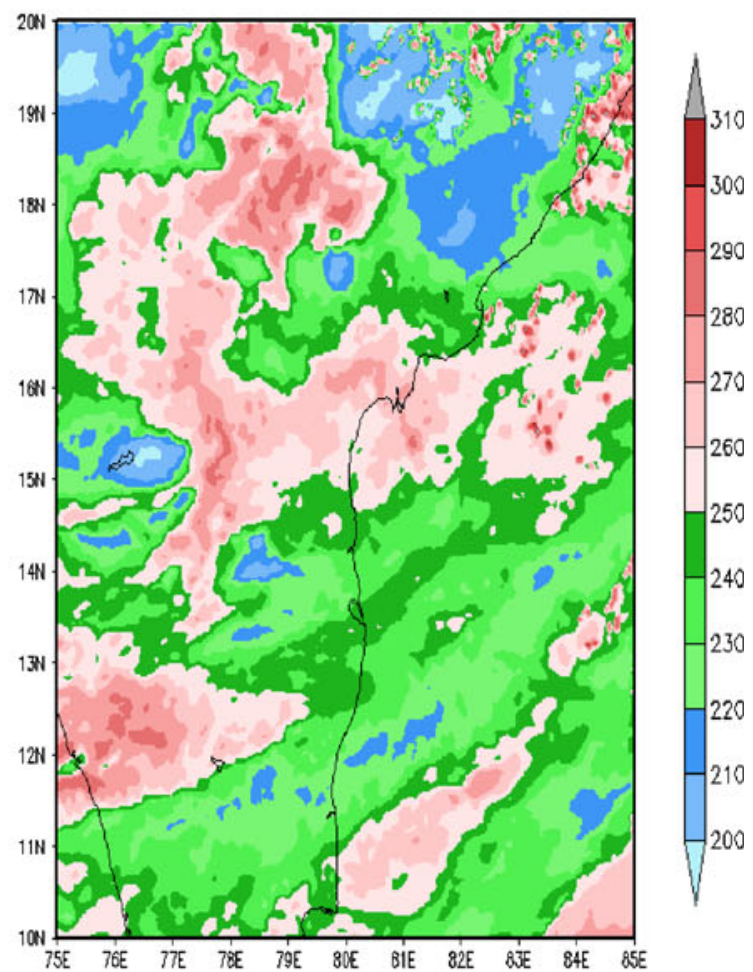

(b) Globally merged IRTB

TIR BRIGHTNESS TEMPERATURE 01SEP2012 0000 UTC

Figure 7. Images of domain-V with deep convective (a, b) and non-deep convective cases (c, d) of Kalpana-1 and globally merged IRTB (infrared brightness temperature data). 
from convective systems of each of the seasons. The applicability of Johnson SB continuous function on globally-merged IRTB data of Climate Prediction Centre NCEP/NWS shows that, Johnson $\mathrm{SB}$ function is flexible to distribute IRTBs data of Kalpana-1, GOES-8/10, and METEOSAT-7/5 and GMS satellites as well. This study may be extended for other satellites IRTBs data to confirm the best fit of Johnson SB continuous function. The Johnson SB function may be used along with the conventional methods of clouds discrimination. It may improve the classification of deep-convective clouds from IRTBs. The utility of Johnson SB function in defining the convective cloud IRTB distribution can be assessed by extensive comparative studies in the future.

\section{References}

Arking A 1964 Latitudinal distribution of cloud cover from Tiros III photographs; Science 143 569-572.

Falls L W 1974 The Beta distribution: A statistical model for world cloud cover; J. Geophys. Res. 79(9) 1261-1264, doi: 10.1029/JC079i009p01261.

Henderson-Sellers A 1978 Surface type and its effect upon cloud cover: A climatological investigation; $J$. Geophys. Res. 83(C10) 5057-5062, doi: 10.1029/ JC083iC10p05057.

Johnson N L 1949 Systems of frequency curves generated by methods of translation; Biometrika 36 149-176.

Johnson N L and Kitchen J O 1971 Some notes on tables to fascilitate fitting SB curves; Biometrika $\mathbf{5 8}$ $223-226$.

Johnson N L, Kotz S and Balakrishnan N 1994 Continuous univariate distributions; Vol. 1, Wiley, New York.
Kanji G K 2006100 Statistical techniques, Sage Publications.

Koffler R, DeCotiis A G and Rao P K 1973 A procedure for estimating cloud amount and height from satellite infrared radiation data; Mon. Weather Rev. 101 240-243.

Koren I and Joseph J H 2000 The histogram of the brightness distribution of clouds in high-resolution remotely sensed images; J. Geophys. Res. 105(D24) 29,369-29,377.

Koslowsky D A 1997 Cloud screening algorithm for daytime AVHRR data using dynamic thresholds; Adv. Space Res. 3 533-536.

Kotteguda N T 1987 Fitting Johnson SB curve by method of maximum likelihood to annual maximum daily rainfalls; Water Resour. Res. 23 728-732.

Mage D T 1980 An explicit solution for Johnson SB parameters using four percentile points; Technometrics $\mathbf{2 2}$ 247-251.

Minnis P and Harrison E F 1984 Diurnal variability of regional cloud and clear sky radiative parameters derived from GOES data: I Analysis method; J. Clim. Appl. Meteorol. 23 993-1011.

Roca R and Ramanathan V 1999 Scale dependence of the monsoonal convective systems over the Indian Ocean; J. Climate 13 1286-1298.

Shapiro S S and Wilk M B 1965 An analysis of variance test for normality (complete samples); Biometrika 52(3/4) 591-611.

Seze G and Desbois M 1987 Cloud cover analysis from satellite imagery using spatial and temporal characteristics of the data; J. Clim. Appl. Meteorol. 26 287-303.

Stanley Q Kidder and Thomas H Vonder Haar 1995 Satellite meteorology: An introduction; Academic Press, pp. 269-273.

Stephens M A 1986 Tests based on EDF statistics; In: Goodness-of-fit Techniques (eds) D'Agostino R B and Stephens M A, chapter 4, Marcel Dekker, Inc. New York.

Zhang L, Packard P C and Liu C 2003 A comparison of estimation methods for fitting Weibull and Johnson's SB distributions to mixed spruce-fir stands in northeastern North America; Can J. Forest Res. 33 1340-1347. 